\title{
LA PARTICIPACIÓN EN POLÍTICA DE LA MUJER: UN ESTUDIO DE CASO
}

\author{
Amparo Novo Vázquez Mercedes Cobo Carrasco Luis A. Gayoso Rico
}

\begin{abstract}
RESUMO
Más de un siglo después de haberse iniciado la lucha de las sufragistas por la superación de la desigualdad politica femenina, todavia hoy se siguen observando diferencias en las oportunidades de acceso de la mujer a los puestos de poder político, a pesar de que a partir de mediados los años ochenta se introduce el sistema de cuotas en España, de la mano del Partido Socialista Obrero Español (PSOE), para conseguir el aumento de la representación femenina y de la paridad. En este trabajo partimos de la hipótesis de que el sistema de cuotas ha favorecido el acceso de las mujeres a las listas de los partidos pese a que siguen teniendo dificultades para incorporarse a cargos legislativos. De este modo, con el objetivo de saber cuál es la presencia de la mujer en ámbitos de toma de decisión en el presente artículo se analiza empíricamente la relación entre militancia y participación en órganos directivos y la relación entre militancia y acceso a puestos de representación observándose cómo el PSOE consigue un mayor equilibrio entre militancia, participación en órganos directivos y acceso a puestos de representación debido al uso del sistema de cuotas. Del mismo modo, y desde la perspectiva cualitativa consideramos la opinión de mujeres políticas, a través de grupos de discusión, que confirmaron nuestra hipótesis de partida, sobre todo para el caso de los partidos progresistas. Así, algunas mujeres pueden ser candidatas, pero debido a la pésima posición que ocupan en las listas llegar a diputadas es mucho más dificil.
\end{abstract}

PALAVRAS-CHAVE: participación politica; afiliación; sistema de cuotas; ejecutivas de partidos.

\section{INTRODUCCIÓN}

Nuestro estudio forma parte de una investigación sobre la presencia y representación de mujeres en cargos ejecutivos, legislativos y en la administración pública en Asturias realizada en el año 2006. En el presente artículo pretendemos exponer la evolución del acceso de las mujeres a puestos de representación política en nuestra comunidad desde la celebración de las primeras elecciones autonómicas en 1983 hasta 2003.

El Principado de Asturias es una comunidad autónoma uniprovincial del Estado Español, constituida en 1982 según el procedimiento establecido en el artículo 143 de la Constitución. Las elecciones autonómicas, que tomamos como referencia en este trabajo, están reguladas por la Ley 14/1986 de 26 de diciembre sobre Régimen de Elecciones a la Junta General del Principado de Asturias. La Junta General del Principado de Asturias (o Parlamento) se compone de 45 diputados. Los electores asturianos, al efecto de repartir esos escaños, están distribuidos en tres circunscripciones: Centro, Occidente y Oriente. A cada una de ellas le corresponden dos diputados y se distribuyen los 39 restantes entre las tres en proporción a su población de derecho. En otro orden de cosas es importante señalar que Asturias posee una estructura socioeconómica peculiar, apoyada sobre la presencia dominante durante varias décadas de la empresa pública en los sectores tradicionales de la industria, que a su vez ha propiciado la conformación de una política característica en determinados aspectos, y ha influido decisivamente en el perfil y la vida interna de los partidos, sobremanera los de izquierda, en su relación con los poderosos sindicatos (BUZNEGO, 1998, p. 81).

A lo largo de las últimas décadas, de la mano del régimen constitucional vigente, se ha registrado dentro de nuestro país un cambio sustantivo en la incorporación de la mujer a todos los espacios sociales y de discusión pública, acompañado de la correspondiente adaptación jurídica que avala dicho cambio. Ahora bien, la radical división del trabajo arraigada en la sociedad capitalista ha 
supuesto para la mujer toda una serie de limitaciones que afectan a su intervención en la vida pública, reducida en ocasiones a temas y aspectos relativos a la protección familiar y al bienestar social, dando lugar al llamado "techo de cristal" o a la discriminación en los procesos de reclutamiento político. A la política no se accede por un sistema meritocrático, es un sistema de cooptación o red informal que no valora la destreza y capacidad objetiva sino la adecuación del candidato/a a un perfil preconcebido (VALCÁRCEL, 2008, p. 98).

La baja participación de la mujer en política (partidos políticos y parlamentos) suele entenderse como el resultado de las diferencias de género en la socialización y en la situación de empleo (MORALES, 2000). El problema se ha desencadenado debido a que los individuos participan activamente en la reproducción social y cultural de los estereotipos de género consolidados a través del proceso de socialización diferencial según sexo (NOVO, 2008, p. 46). De este modo, la baja proporción de mujeres entre las personas encargadas de adoptar decisiones obedece a la existencia de barreras tanto estructurales - acceso limitado a vías tradicionales de poder como los órganos de decisión de partidos políticos, organizaciones patronales y sindicatos - como ideológicas, que deben superarse mediante la adopción de medidas positivas orientadas a eliminar la persistente infra-representación y, algunas veces, la marginalización de las mujeres en la vida política (CONDE, 2000, p. 239). Más presencia de mujeres contribuiría a erradicar la idea de que la política es un asunto de hombres (CAMPBELL \& WOLBRECHT, 2006).

En el presente artículo partimos de la hipótesis de que el sistema de cuotas ha favorecido el acceso de las mujeres a las listas de los partidos, pero las mujeres siguen teniendo dificultades para incorporarse a cargos ejecutivos debido a la estrategia seguida por los partidos políticos en el proceso de reclutamiento. En una primera aproximación al tema veremos cuál es la afiliación y presencia de la mujer en las ejecutivas de los partidos y en el Parlamento, y cómo el sistema de cuotas ha influido en el creciente número de las mismas. Veremos cuál ha sido la posición de las mujeres en las listas elaboradas por los partidos políticos, ya que éstos son los principales impulsores del individuo hacia los puestos repre- sentativos y cómo ha influido en su posibilidad de conseguir un puesto de toma de decisión. Además de la presentación de datos cuantitativos introducimos la perspectiva cualitativa en el estudio, a través de grupos de discusión, con la intención de saber la opinión de hombres y mujeres vinculados a la política acerca de los efectos del sistema de cuotas en la política asturiana y del procedimiento de nominación de candidatos en los partidos. En concreto, se realizaron tres grupos de discusión ${ }^{1}$ para obtener un material empírico donde quedaran reflejadas y representadas las distintas voces que componen los altos niveles políticos y técnicos en Asturias. Los grupos fueron mixtos en su composición interna, aunque con mayor presencia femenina, lo que permitió que se cumplieran los criterios buscados de profundidad y pluralidad en las opiniones expresadas y representadas en los discursos resultantes (ARENAS, 2006). Además del género, la selección de los participantes en los grupos combinó varios criterios: partido político (representantes del Partido Socialista Obrero Español, Partido Popular e Izquierda Unida, que abarcan la práctica totalidad del arco político), nivel de responsabilidad (parlamentarios, consejeros y altos cargos de la administración), pertenencia a formaciones políticas y asociativas, tramo de edad, circunscripción electoral, etc.

\section{ESTRATEGIAS PARTIDISTAS DE PROMO- CIÓN DE LAS MUJERES PARA OCUPAR PUESTOS DE RESPONSABILIDAD}

Los partidos son los principales actores involucrados en el proceso de selección de elites (COTARELO, 1985; PANEBIANCO, 1990). Su objetivo prioritario no es otro que la captación de un amplio abanico de votantes que les permita obtener la victoria electoral, lo que les lleva a articular distintas estrategias de promoción de las mujeres, tanto en la organización del partido como en los cargos de representación política. De ahí que las reivindicaciones femeninas ocupen un lugar importante en las campañas electorales, así como sus exhortaciones, más o menos retóricas,

$11^{\text {o }}$ grupo realizado el 13 de marzo de 2006 a las 17 horas en la Sala de Prensa del Rectorado de la Universidad de Oviedo; $2^{\circ}$ grupo realizado el 16 de marzo de 2006 a las 18:30 en idéntico escenario; y $3^{\circ}$ grupo realizado el 21 de marzo de 2006 a las 18:30 en la Sala Schumpeter de la Facultad de Ciencias Económicas y Empresariales de la Universidad de Oviedo. 
a la incorporación de las mujeres a la política (LOVENDUSKI, 1997, p. 121). Como más adelante veremos, los partidos presentan diferencias significativas en cuanto a las medidas de discriminación positiva, pero todos ellos se muestran partidarios de favorecer la representación de las mujeres en los puestos de toma de decisión mediante requerimientos para que figuren en las listas electorales y, llegado el caso, mediante medidas de racionalización de los tiempos de trabajo y dedicación familiar de todos los parlamentarios, etc.

Pero la manera concreta en que cada uno de los partidos materializa este tipo de reivindicación varía extraordinariamente. Así, por ejemplo, Izquierda Unida (IU) ha incluido en su programa distintas medidas para solventar la discriminación de género en el mundo político (IZQUIERDA UNIDA, 1993, p. 108), con el objetivo de poner fin a la visión masculina del poder y a la invisibilidad y la marginación femeninas en el modelo económico y político. Esta reivindicación parte del supuesto de que sin el protagonismo social, político, económico y cultural de las mujeres no se podrá alcanzar la democracia plena. Las medidas propuestas para conseguir la igualdad de sexos se concretan en la elaboración y desarrollo de Planes de Igualdad de Oportunidades ${ }^{2}$ y el apoyo y fomento a la participación social y política igualitaria a través de la promoción del asociacionismo de mujeres, la dinamización del Consejo Asturiano de la Mujer y los incentivos encaminados la paridad entre hombres y mujeres en las listas electorales (IZQUIERDA UNIDA, 2004, p. 33).

Tal objetivo pasa por la consecución de la igualdad entre hombres y mujeres y por el funcionamiento de la organización como un movimiento político y social en constante diálogo con la sociedad, dentro del cual se combinen sensibilidades nuevas de carácter feminista y que se faciliten los procesos de participación e incorporación de las mujeres a todos los ámbitos públicos, promoviendo para ello actividades e iniciativas específicas dirigidas a la participación y afiliación femenina. En 2004 se hace un

2 Según López Guerra (2000, p. 40), los "Planes de Igualdad de Oportunidades" son una iniciativa pública de acción compensatoria dentro de una versión "blanda" de la acción positiva. llamamiento desde IU a todas las Federaciones y Asambleas para emprender una intensa campaña de afiliación. Al mismo tiempo se establece que en los órganos de dirección, candidaturas, comisiones, etc., ninguno de los dos sexos podrá superar el porcentaje del 60\% (idem, p. 1-2).

Bien distinta es la filosofía del Partido Popular (PP) en materia de participación de las mujeres, más allá de la consabida declaración de principios a favor de dicha participación. Frente a la política de cuotas y al establecimiento de criterios de paridad, el PP pone el énfasis en los derechos individuales y en la igualdad de oportunidades: "Las mujeres y los hombres que formamos el PP no creemos en la falsa democracia paritaria que solo sirve para maquillar las desigualdades de la mujer, pero no ataca el problema. En vez de eso apostamos por su igualdad total y plena en todos los sectores, también en nuestro partido, según criterios de méritos y capacidad, y sobre la base de la igualdad del hombre y la mujer, de los derechos humanos y las libertades fundamentales en la esfera política, económica, cultural y social" (PARTIDO POPULAR, 2004, p. 8). Se considera prioritario desarrollar, entre todas las instituciones, políticas que eliminen cualquier tipo de discriminación de la mujer tratando de asegurar la igualdad de oportunidades como objetivo final (PARTIDO POPULAR, 1999, p. 57).

En su programa electoral se deja constancia de que las políticas son globales para todos los ciudadanos en cada una de las áreas, aunque se hace mención expresa de acciones positivas muy concretas y específicas para determinados colectivos que las precisan por razones de género; en este sentido, el Partido Popular de Asturias concentra su actuación en tres campos muy concretos: mujer rural, mujer y empleo y violencia sobre mujeres. En cuanto a la afiliación, no hay ninguna intención precisa y explícita de atraer militancia femenina a su partido.

Por lo que se refiere al Partido Socialista Obrero Español (PSOE), hay que decir que las medidas enfocadas a la representación igualitaria entre hombres y mujeres han sido intensivas y permanentes desde los años noventa (aprobación de la cuota del $25 \%$ en el XXXI Congreso Federal, enero de 1988). En aquellas instituciones gobernadas por los socialistas (PARTIDO SOCIALISTA OBRERO ESPAÑOL, 2004, p. 63) se ha contado con importantes instrumentos de apoyo articulados y 
desarrollados a través de los Planes de Igualdad de Oportunidades de las Mujeres ${ }^{3}$ aprobados y puestos en marcha por los distintos gobiernos en el Estado español, la autonomía y los municipios. Los socialistas asumen e impulsan desde las instancias de gobierno el nuevo "Contrato Social Mujeres-Hombres", que propone compartir las responsabilidades familiares, el trabajo y el poder (PARTIDO SOCIALISTA OBRERO ESPAÑOL, 1999, p. 103). El crecimiento de la afiliación es uno de los objetivos del partido, que ha puesto en práctica un programa específico de afiliación e incorporación de simpatizantes (PARTIDO SOCIALISTA OBRERO ESPAÑOL, 2004, p. 66).

¿Cuáles son los resultados de estas distintas estrategias de captación del electorado femenino en términos de afiliación? Tal como corresponde a partidos con diferente implantación electoral, el volumen de militancia varía significativamente entre uno y otro, en cantidades que oscilan entre los 20787 militantes declarados por el PP y los 4 911 de IU (entremedias, se sitúa el PSOE con 10
009). Ahora bien, más llamativo resulta el dato de que sea el PP el que, siendo el menos entusiasta de la discriminación positiva, sea al mismo tiempo el que presenta una mayor proporción de mujeres militantes (7 638 mujeres, $36,7 \%$ del total $)^{4}$, seguido del PSOE (3 137, 31,34\% del total) ${ }^{5}$. Curiosamente, es el partido que ofrece un planteamiento más maximalista en esta materia (IU) el que presenta la menor proporción de militancia femenina $(1495,30,44 \% \text { del total })^{6}$.

Esta información relativa a la militancia femenina en los partidos políticos está recogida en la Tabla 1 , que nos informa también de la representación obtenida por esta militancia en las direcciones de cada uno de los partidos. También en este punto se observan diferencias significativas entre ellos, de tal manera que mientras uno de los partidos, el PSOE, tiende a sobre-representar a sus mujeres militantes hasta cubrir las exigencias mínimas de la paridad (40\%), los demás partidos, tan distintos en su filosofía, coinciden en infra-representar a sus mujeres en los órganos directivos.

TABLA 1 -AFILIACIÓN Y PRESENCIAFEMENINA EN LAS EJECUTIVAS DE LOS PARTIDOS (2006)

\begin{tabular}{|l|c|c|c|}
\hline PARTIDOS & $\begin{array}{c}\text { N. TOTAL DE } \\
\text { AFILIADOSEN } \\
\text { ASTURIAS }\end{array}$ & $\begin{array}{c}\text { N. DE MUJERES } \\
\text { AFILIADAS EN } \\
\text { ASTURIAS (\%) }\end{array}$ & $\begin{array}{c}\text { N. DE MUJERES EN } \\
\text { LAS EJECUTIVAS DE } \\
\text { LOS PARTIDOS (\%) }\end{array}$ \\
\hline PSOE & 10009 & $3137(31,34 \%)$ & $13(39,4 \%)$ \\
IU & 4911 & $1495(30,44 \%)$ & $3(20,0 \%)$ \\
PP & 20787 & $7638(36,7 \%)$ & $11(25,6 \%)$ \\
\hline
\end{tabular}

FUENTE: Elaboración propia a partir de los datos facilitados por el Parlamento de Asturias y partidos políticos.

NOTA: Significado de las siglas: PSOE: Partido Socialista Obrero Español; IU: Izquierda Unida; PP: Partido Popular.

En IU las decisiones fundamentales a nivel organizativo y ejecutivo se adoptan en el Consejo Político Federal y en la Asamblea. El primero es el máximo órgano de dirección y decisión entre asambleas, y está formado por 47 mujeres (30\%) y 111 hombres (70\%). La Asamblea es un estamento más restringido y en él participan tres mujeres $(20 \%)$ y 12 hombres $(80 \%)$.

En el caso del Federación Socialista Asturiana (FSA-PSOE), la Comisión Ejecutiva Regional es el máximo órgano ejecutivo y está compuesto por 33

\footnotetext{
3 El I Plan para la Igualdad de Oportunidades de las mujeres se desarrolló en 1988 y finalizó en 1991.
}

miembros, de los cuales 20 son hombres (61\%) y $13(39 \%)$ son mujeres. Forman parte de la Comisión las 19 secretarías regionales representadas por once hombres y ocho mujeres. Los militantes socialistas que ostentan los cargos de Presidencia del Consejo de Gobierno del Principado, la Portavocía del Grupo Parlamentario y la Secretaría General de las Juventudes, miembros natos de la Comisión Ejecutiva, son varones en todos los casos.

\footnotetext{
4 Datos facilitados por Santiago Gómez Palomar, jefe de datos del PP el 3 de octubre de 2006.

5 Datos de 30 de junio de 2005 facilitados por el partido.

6 Datos de 16 de junio de 2006 facilitados por IU.
} 
El Comité Ejecutivo Regional es el principal órgano decisorio en el PP asturiano. Está compuesto por 43 miembros, 11 mujeres $(26 \%)$ y 32 varones $(74 \%)$.

Los valores más destacados de participación femenina en cargos ejecutivos - 39,4\% de mujeres - se observan en el FSA-PSOE, bordeando los niveles de la paridad. En el PP, ese porcentaje se reduce a sólo la cuarta parte de la directiva. $\mathrm{Y}$ en la Asamblea Ejecutiva de IU se aprecia una participación femenina aún menos significativa sólo uno de cada cinco miembros de la misma es una mujer.

Una vez que hemos estudiado la relación entre militancia y participación en órganos directivos, vamos a pasar ahora a estudiar la relación entre militancia y acceso a puestos de representación. En este caso, la comparación entre los partidos se invierte respecto a lo observado en la Tabla 1, toda vez que es ahora el PP el que presenta un mayor grado de infra-representación de las mujeres en puestos de representación (por comparación con su militancia), por contraste con IU, donde las mujeres alcanzan el mayor grado de sobrerepresentación. En una posición intermedia, sigue estando el PSOE, que consigue una ajustada correspondencia entre militancia femenina y acceso a puestos de representación.

En la Tabla 2 se puede observar la relación entre la presencia de mujeres representantes de cada uno de los tres grandes partidos políticos en la Cámara autonómica asturiana y los diferentes porcentajes de afiliación femenina, utilizando en ambos casos datos correspondientes al año 2006. Se comprueba que el PP infra-representa claramente a las mujeres en el Parlamento, ya que el peso relativo de afiliadas sobre el total $(36,7 \%)$ supera en más de 15 puntos porcentuales al de diputadas autonómicas. En el PSOE, el porcentaje de parlamentarias supone un peso relativo más o menos equivalente al que representan las mujeres sobre el total de afiliación. En IU se aprecia, tal como adelantamos, una clara sobre-representación de las mujeres en el Parlamento Autonómico, pasándose de un $30 \%$ de afiliación femenina a un $75 \%$ de presencia de mujeres en el grupo parlamentario del partido.

TABLA 2 - REPRESENTACIÓN FEMENINA EN LA JUNTA GENERAL DEL PRINCIPADO EN RELACIÓN ALA AFILIACIÓN FEMENINA

\begin{tabular}{|l|c|c|c|}
\hline PARTIDOS & $\begin{array}{c}\text { N. TOTAL DE } \\
\text { AFILIADOSEN } \\
\text { ASTURIAS }\end{array}$ & $\begin{array}{c}\text { N. DE MUJERES } \\
\text { AFILIADAS EN } \\
\text { ASTURIAS (\%) }\end{array}$ & $\begin{array}{c}\text { N. DE MUJERES EN } \\
\text { LAS EJECUTIVAS DE } \\
\text { LOS PARTIDOS (\%) }\end{array}$ \\
\hline PSOE & 10009 & $3137(31,34 \%)$ & $13(39,4 \%)$ \\
IU & 4911 & $1495(30,44 \%)$ & $3(20,0 \%)$ \\
PP & 20787 & $7638(36,7 \%)$ & $11(25,6 \%)$ \\
\hline
\end{tabular}

FUENTE: Elaboración propia a partir de los datos facilitados por el Parlamento de Asturias y partidos políticos.

En conjunto, podemos concluir que el PSOE parece conseguir un mayor equilibrio entre militancia, participación en órganos directivos y acceso a puestos de representación, debido al uso que hace del sistema de cuotas. Desde este punto de vista, el dato más sorprendente es el contraste entre PP, donde las mujeres militantes están infrarepresentadas en los órganos de decisión y, sobre todo, en los puestos de representación, e IU, donde las mujeres militantes están infra-representadas en los órganos de decisión, pero sobre-representadas en los puestos de representación. Este contraste se explica por la influencia de los movimientos feministas en el seno de los partidos de izquierda, a través del sistema de cuotas y de medidas de discriminación positiva (URIARTE, 1995).

III. ANÁLISIS DE LOS EFECTOS DEL SISTEMA DE CUOTAS EN LA VIDA POLÍTICA ASTURIANA

La escasa participación en política de las mujeres se ha convertido en un problema de legitimación que involucra a las democracias 
actuales; para atenuar su exigua presencia en puestos de toma de decisión se institucionalizó el sistema de cuotas, como medida de acción positiva que podría permitir feminizar la política (VALCÁRCEL, 1997, p. 100-101). Es a partir del Tratado de Amsterdam cuando se hace efectiva la exigencia de la acción positiva en el acceso y la promoción en los cargos representativos (FREIXES, 1999). Surgirá el concepto de democracia paritaria, remitiéndonos éste a las distintas medidas que se pueden adoptar como compensación de la discriminación que en este campo ha vivido la mujer. La paridad política no es sólo una cuestión de números y porcentajes, sino un aspecto clave de la democracia actual y, por tanto, de los derechos fundamentales de las mujeres (TRUJILLO, 2000, p. 355). En definitiva la democracia paritaria ${ }^{7}$ persigue una representación política que sea igual para uno y otro sexo.

En las últimas décadas se han ido extendiendo los planteamientos que, yendo más allá de las cuotas, proponen una igualdad entre sexos dentro del ámbito del poder político que se establezca a partir de la llamada democracia paritaria, que se basa en la idea de una atribución igualitaria de escaños, puestos de gobierno y demás altos cargos de responsabilidad. Si las cuotas hacían referencia a una igualdad a nivel de listas y candidaturas, la paridad reclama esa misma igualdad pero a nivel de resultados electorales.

En los grupos de discusión surgió el debate, iniciado por representantes del PSOE, sobre la conveniencia de conseguir una representación igualitaria que enriqueciera el discurso y la vida política con un nuevo enfoque formalizado por mujeres, además de romper estereotipos instalados en la sociedad, animando a las mujeres a participar en un mundo tradicionalmente representado por hombres: "[...] pero las cuotas es al final simplemente un instrumento del cual se dota una organización para corregir desigualdades. Y la verdad es que la realidad demuestra que por un lado permite tener una masa crítica de mujeres... que facilite el debate y que se lleve a

\footnotetext{
7 Respecto a las consecuencias que se le pueden imputar a la democracia paritaria por ser mal comprendido el sistema de cuotas puede verse entre otros (BIGLINO, 2000, p. 409-429).
}

la reflexión política el punto de vista de las mujeres, que todavía en la sociedad estamos viviendo más en el ámbito privado que en el público, y por lo tanto tenemos una perspectiva un poco diferente; ayuda a hacer referencia de que sí se puede estar en política e incluso y anima a las mujeres. Yo sería partidaria, para mi lo ideal sería una participación en la que no fuese necesario, pero lo va a seguir siendo" (mujer, PSOE, grupo de discusión 2).

Entre las medidas adoptadas para la corrección de desigualdades la reserva de cuotas en las listas electorales es una variedad de acción positiva ${ }^{8}$, con carácter temporal, denominada "discriminación inversa" (REY, 1995; GUERRA, 2000). Como señala Rey la finalidad de la discriminación inversa es remediar los efectos negativos de las discriminaciones profundamente arraigadas en la sociedad, no puede ser considerada como una discriminación directa.

Algunos partidos políticos, generalmente los de corte progresista, buscan asegurar espacios reservados para las mujeres a través de cuotas, tanto en las listas electorales como en las estructuras organizativas de decisión política (LOVENDUSKI, 1997). Los partidos conservadores son renuentes a la aplicación de esta medida de corrección. Si hacemos historia, el PSOE fue el primer partido en España, a fines de los años 1980, en introducir el sistema de cuotas $(25 \%)$ para incorporar mujeres al partido y a sus órganos de representación, así como en todos los cargos y responsabilidades políticas que los socialistas ocuparan. En 1997 se aprueba la democracia paritaria, y se contempla que ningún sexo puede estar representado por debajo del $40 \%$ ni por encima del $60 \%$ en cualquier órgano de dirección, control o ejecutivo del Partido. En el caso de IU, asumida la democracia paritaria, ningún sexo debe ocupar más del $60 \%$ de los puestos en los órganos de dirección y en las listas electorales ${ }^{9}$. El Partido Popular, por el contrario, no es partidario

8 En base al mandato del artículo $14 \mathrm{CE}$, de prohibición de
discriminación contra la mujer, el Tribunal Constitucional
considera adecuado tratamientos que conceden a la mujer
ventajas como grupo desfavorecido.
9 Esta medida fue recogida en la V Asamblea Federal de IU,

9 Esta medida fue recogida en la V Asamblea Federal de IU, 
del sistema de cuotas, pero mediante reglas no oficiales incluyen en sus órganos internos y en sus listas electorales un porcentaje de mujeres significativo. Es importante que un partido muestre la voluntad de incrementar el número de mujeres, ya que hay muchas probabilidades de que los demás integrantes del sistema de partidos actúen de igual modo (ELIZONDO, 1997, p. 98). En los sistemas de representación proporcional es más factible que se resuelva un proceso de contagio entre partidos ideológicamente próximos adoptando políticas iniciadas por otros (MATLAND \& STUDLAR, 1996; RÍOS, 2006).

Las cuotas son efectivas para garantizar la inclusión de mujeres en las cámaras de representación nacional, tal como revela el estudio realizado por Sánchez Medero (2007). Del mismo modo es evidente que las cuotas han incidido favorablemente en la mayor presencia femenina en la realidad política asturiana y, de hecho, su trascendencia ha sido reafirmada por los partidos de izquierda en los grupos de discusión. Los representantes de PSOE e IU creen que la implantación de cuotas es el motor principal para la incorporación de la mujer a la vida política, las consideran integracionistas y enriquecedoras. Por contra, el PP es reacio a considerar las cuotas como sistema eficaz; las definen como incompatibles con el principio de igualdad y el derecho a la no discriminación por razón de sexo, y apoyan, en parte, su argumentación en el principio meritocrático, es decir, en que han de ser las propias capacidades de las mujeres - y hombres - las que se valorarán en el proceso de reclutamiento y selección.

Para ilustrar esta opinión se suele hacer referencia a que han existido esferas de poder público en las que la mujer ha logrado una presencia casi paritaria, tan sólo en base a los principios de mérito y capacidad, sin ningún tipo de cuota, como puede ser la Administración General del Estado y en el sistema judicial (BIGLINO, 2000, p. 425): "Nosotros como sabéis no [...] no tenemos paridad, porque nosotros creemos que da igual, es decir, lo que queremos es que se elija a las personas por su valía personal, entonces [...] puede ser el $60 \%$ o el $70 \%$ de mujeres si hay suficientes eh? De hecho en Gijón, tenemos seis concejalas y cinco concejales de manera que en Gijón tenemos más mujeres que hombres" (mujer, PP, grupo de discusión 2).

A través de los grupos de discusión organizados se han podido observar los distintos posicionamientos de la elite política asturiana ante el sistema de cuotas. Valorar y destacar el importante papel de la feministas en la lucha por las cuotas de participación fue reconocido por todas y todos los representantes de los partidos de izquierdas. A partir de aquí sus discursos se dirigieron por un lado, hacia el reconocimiento evidente de sus efectos positivos en cuanto al aumento de la representación y de la afiliación a los partidos políticos, y por tanto, en la presencia de mujeres en puestos de toma de decisión: "[...] Nuestras compañeras feministas empiezan a luchar por la cuota y nuestros compañeros de partido la aceptan, es a partir de ese momento que la representación de la mujer en política es muchísimo mayor, pero es que esa representación en la vida política [...] esa representación se ve también por el índice de afiliadas a los partidos políticos" (mujer, PSOE, grupo de discusión 2).

Esta medida de acción positiva ayudó a incrementar su presencia en la vida política pero además la sociedad española ha evolucionado de forma considerable en cuanto a la concepción de un papel de la mujer en el ámbito público y político: "las cuotas... reconozco que cubrieron un papel importante, yo creo que si hay más mujeres ahora se debe a esas obligaciones que los partidos se pusieron a sí mismos de incluir mujeres $[\ldots]$ pero también influye, que la sociedad española en general dio un salto enorme desde la llegada de la democracia.. Esos cambios en la sociedad permitieron ver como muchísimas mujeres tenían una enorme capacidad para estar en lugares, en las instituciones, en las direcciones de los partidos y demás" (mujer, IU, grupo de discusión 1).

Por otro lado conviene destacar que tanto los hombres como las mujeres conservadoras están en total desacuerdo con esta medida de acción positiva, debido a que para ellos es la vocación política de las mujeres lo que hace que estén re- 
presentando al pueblo; las que no están, se explica por la falta de interés por pertenecer al mundo político. Sólo uno de los varones participantes expresó que el supuesto de admitir cuotas sería para aquellas mujeres que tienen cargas familiares, que son las que verdaderamente tienen problemas para poder desarrollar plenamente las responsabilidades políticas que un cargo de estas características requeriría: "el establecer cuotas políticas... es hacer la casa por el tejado, no soluciona estructuralmente el problema. Se está primando a unas mujeres que en principio no tienen ningún inconveniente en relación con los hombres para competir... para competir con los hombres... Las cuotas no representan realmente a las mujeres con problemas: una chica soltera ¿que diferencia tiene hoy en día con un chico soltero sin hijo bueno, soltero o sin pareja, vamos o sin cargas familiares - para competir en un ámbito político o profesional?, ninguna. O sea, las que tenéis problemas sois las que tenéis cargas familiares, bueno, pues de establecer cuotas, establecer una cuota para mujeres con cargas familiares. El establecer una separación es entrar en una democracia paritaria, o sea ya no [...] somos todos iguales: hombres y mujeres" (varón, PP, grupo de discusión 2).

IV. LA POSICIÓN DE LAS MUJERES EN LOS PARTIDOS POLÍTICOS Y SU REPERCUSIÓN EN LA REPRESENTACIÓN PARLAMENTARIA

La ideología del partido político así como su organización delimita el proceso de reclutamiento de las elites y las posibilidades de elegibilidad de las mujeres (ERICSSON, 1993; LOVENDUSKI, 1993; 1995; MATLAND, 2003; NORRIS, 2004; LOIS, 2008). Dadas las tendencias oligárquicas de los partidos, sus elites dirigentes suelen ser los principales garantes de su funcionamiento. De acuerdo con el primer gran estudioso de dichas tendencias oligárquicas (MICHELS, 1979), toda organización precisa de un aparato burocrático, toda vez que el grueso de la militancia no suele tener la preparación adecuada ni la motivación suficiente para dedicar esfuerzos a la vida pública. Producto de la tradición, la mayoría de las ejecutivas de los partidos están representadas mayoritariamente por hombres, lo que se traduce a veces en discriminación de las mujeres, que quedan relegadas de los puestos decisorios (como se señaló arriba, a excepción del PSOE).
Esto trae a veces como consecuencia un acceso de las mujeres a los puestos de liderazgo condicionado y mediatizado a causa del control ejercido por los partidos políticos sobre el proceso de nominación de candidatos. Elaboran las listas de candidatos a cargos de representación política $y$, en este sentido, actúan como "filtros"10. Así nos lo han hecho saber a través de las discusiones mantenidas con ellas y ellos: "[...] quién toma las decisiones en el partido, porque ejemplos conocemos de mujeres que están ahí, pero las decisiones importantes las toman los núcleos de poder, las ejecutivas, donde están mayoritariamente todavía hombres" (mujer, PSOE, grupo de discusi? n 3).

Todo partido político cuenta con una doble estructura formal e informal. Así, dentro de esta última los miembros toman decisiones, movilizan a sus miembros para que establezcan distintas líneas de actuación con el electorado, a través de recursos y prácticas que faciliten la proximidad y el diálogo, estableciéndose de esta forma un vínculo entre estos y los demás miembros del partido. La disposición interna de los partidos en diferentes redes, sustentadas por sólidas tendencias ligadas a su propia historia, sean estas ideológicas, de familias, económicas, sindicales, etc., individualiza a cada organización política. La rivalidad por alcanzar un mayor espacio de poder y prestigio a base de conseguir más adeptos a sus filas es una característica de las redes de grupos, por ello los militantes son el objetivo prioritario de competencia. Por otro lado, es habitual recurrir a colegas para nombramientos o cargos allí donde funcionan las relaciones informales (OSBORNE, 2005).

Los siguientes testimonios dan cuenta de algunos de estos aspectos que hemos subrayado: "las listas se hacen por oportunidades políticas y basadas en eso, en que ganamos todos" (varón, PP, grupo de discusión 3); "Yo creo que las listas no se hacen sólo por oportunidades políticas, muchas veces se hacen, insisto, en todos los partidos, por sensibilidades, por tendencias, por familia" (mujer, PSOE, grupo de discusión 3).

10 Vide Uriarte y Elizondo (1997) y Méndez-Montalvo y Ballington (2002). 
Las mujeres se enfrentan además a la falta de tiempo necesario para realizar tareas o actividades de conquista de nuevos militantes para el partido, debido a la triple jornada ${ }^{11}$; la mayoría de los hombres, por el contrario, disponen de un amplio margen de actuación debido a que sus máximas responsabilidades se encuentran en el ámbito público. De forma elocuente lo significó una política del PSOE: "generalmente, las distintas familias o tendencias, las suelen encabezar casi siempre hombres, entonces, cuando tienes que buscar, o a veces los equilibrios territoriales, fulanito de oriente, el otro de occidente, acaban casi siempre siendo hombres, entonces hay que hacer un esfuerzo, que se puede hacer más o menos consciente, para decir, hombre, no, vamos a ver si buscamos una mujer" (mujer, PSOE, grupo de discusión 3); “[...] cualquier carrera tú la estudiabas y partías de la base de que cuando terminases pues... de una u otra manera accedías al ejercicio. En cambio en la política no. El acceso va por otras vías, a través del contacto con los partidos. Es necesario pienso yo, ocupar primero un cargo largo dentro del mismo. Ese proceso pienso que es lento, es muy muy lento" (mujer, $\mathrm{PP}$, grupo de discusión 1)

El momento trascendental del proceso de selección con respecto a las mujeres ocurre en los procedimientos de nominación; así, si un partido opta por la equidad de género puede fácilmente compensar cualquier predisposición que pudiera existir en el grupo de elegibles (MATLAND, 2003, p. 22). Para poder ver qué es lo que ocurre en Asturias al respecto es necesario describir algunas particularidades del sistema electoral asturiano. Así, la Junta General del Principado de Asturias se compone de 45 diputados. Los electores asturianos, al efecto de repartir esos escaños, están distribuidos en tres circunscripciones: Centro, Occidente y Oriente. A cada una de ellas le corresponden dos diputados y se distribuyen los 39 restantes entre las tres en proporción a su población de derecho. En la circunscripción Centro está agrupado el ocho asturiano, así llamado por la figura que dibujan sobre el territorio los municipios más poblados de la región, al este los de las cuencas mineras y al norte los del triángulo

11 A este respecto puede verse Novo (2009). formado por Oviedo, Gijón y Avilés. Se caracteriza por la actividad industrial y la vida económica y social de Asturias. En total son 29 municipios y los escaños asignados ascienden a 33 desde la IV legislatura (32 en las anteriores). La circunscripción de Occidente es la más próxima a Galicia, su actividad es predominantemente rural y elige a siete diputados. La de Oriente es la más próxima a Cantabria y su actividad fundamental es la agraria y el sector terciario, distribuye 5 escaños (BUZNEGO, 1998, p. 82).

A través de las Tablas 3, 4 y 5 pueden observarse los datos correspondientes a la participación femenina en las listas electorales de los tres grandes partidos políticos que se han presentado en las diferentes circunscripciones asturianas (occidental, central y oriental). Como decíamos, siete son los escaños que se reparten en la Circunscripción Occidental. Como se puede apreciar en la (Tabla 3) los mayores porcentajes de participación femenina se observan para el PSOE a lo largo de las diferentes convocatorias electorales, si bien hasta el año 1999 no se aprecian tantos por cientos significativos de mujeres en los primeros puestos de las listas, y los puestos medios de las candidatas en las mismas son bastante elevados. Es decir, en esta circunscripción el PSOE siempre ha incluido mujeres en la lista, pero sólo desde 1999 es paritaria. Por su parte, tanto para el PP como para IU, los porcentajes de presencia femenina son bastante más reducidos, y casi inexistentes en lo que hace referencia a los primeros puestos de las listas electorales. En el caso del PP incorpora la primera mujer en 1991 en el número cuatro y no vuelve a hacerlo hasta 1999, IU lo hace en 1995.

Para lograr una mayor presencia en puestos relevantes en las listas es necesario que en el espacio político coexistan rutinas sociales que acrecienten y prescriban cambios culturales, ya sean referidos a concepciones enmarcadas en estereotipos y prejuicios sexistas o a la influencia de las estructuras institucionales y la cultura política en las oportunidades femeninas para acceder al poder. El partido político es el responsable del reclutamiento y la selección de los candidatos, y la superación de estas barreras pasa por la interiorización por parte de las ejecutivas de la selección de candidatos de forma democrática, justa y eficiente. 
TABLA 3 - PRESENCIA FEMENINA EN LAS LISTAS ELECTORALES EN LA CIRCUNSCRIPCIÓN OCCIDENTAL, POR PARTIDOS

\begin{tabular}{|c|c|c|c|}
\hline AÑOS & PSOE & PP (AP) & IU (PCA) \\
\hline \multirow[t]{5}{*}{1983} & $\begin{array}{l}\text { - Total Miembros de la } \\
\text { Lista: } 8\end{array}$ & $\begin{array}{l}\text { - Total Miembros de la } \\
\text { Lista: } 8\end{array}$ & $\begin{array}{c}\text { - Total Miembros de la } \\
\text { Lista: } 8\end{array}$ \\
\hline & - No Mujeres: 1 & - No Mujeres: 0 & - No Mujeres: 0 \\
\hline & - \% Mujeres: 12,5\% & - \% Mujeres: 0\% & - \% Mujeres: $0 \%$ \\
\hline & $\begin{array}{l}\text { - \% Mujeres en los } 3 \\
\text { Primeros Puestos: } 0 \%\end{array}$ & $\begin{array}{l}\text { - \% Mujeres en los } 3 \\
\text { Primeros Puestos: } 0 \%\end{array}$ & $\begin{array}{c}\text { - \% Mujeres en los } 3 \\
\text { Primeros Puestos: } 0 \%\end{array}$ \\
\hline & $\begin{array}{l}\text { - Puesto Medio de las } \\
\text { Mujeres en la Lista: } 6\end{array}$ & $\begin{array}{l}\text { - Puesto Medio de las } \\
\text { Mujeres en la Lista:- }\end{array}$ & $\begin{array}{l}\text { - Puesto Medio de las } \\
\text { Mujeres en la Lista:- }\end{array}$ \\
\hline \multirow[t]{5}{*}{1987} & $\begin{array}{c}\text { - Total Miembros de la } \\
\text { Lista: } 8\end{array}$ & $\begin{array}{c}\text { - Total Miembros de la } \\
\text { Lista: } 8\end{array}$ & $\begin{array}{l}\text { - Total Miembros de la } \\
\text { Lista: } 8\end{array}$ \\
\hline & - No Mujeres: 1 & - No Mujeres: 0 & - No Mujeres: 0 \\
\hline & - \% Mujeres: $12,5 \%$ & - \% Mujeres: $0 \%$ & - \% Mujeres: $0 \%$ \\
\hline & $\begin{array}{l}\text { - \% Mujeres en los } 3 \\
\text { Primeros Puestos } 0 \%\end{array}$ & $\begin{array}{l}\text { - \% Mujeres en los } 3 \\
\text { Primeros Puestos: } 0 \%\end{array}$ & $\begin{array}{c}\text { - \% Mujeres en los } 3 \\
\text { Primeros Puestos: } 0 \%\end{array}$ \\
\hline & $\begin{array}{l}\text { - Puesto Medio de las } \\
\text { Mujeres en la Lista: } 5\end{array}$ & $\begin{array}{l}\text { - Puesto Medio de las } \\
\text { Mujeres en la Lista:- }\end{array}$ & $\begin{array}{l}\text { - Puesto Medio de las } \\
\text { Mujeres en la Lista:- }\end{array}$ \\
\hline \multirow[t]{5}{*}{1991} & $\begin{array}{l}\text { - Total Miembros de la } \\
\text { Lista: } 8\end{array}$ & $\begin{array}{c}\text { - Total Miembros de la } \\
\text { Lista: } 8\end{array}$ & $\begin{array}{c}\text { - Total Miembros de la } \\
\text { Lista: } 8\end{array}$ \\
\hline & - No Mujeres: 2 & - No Mujeres: 1 & - No Mujeres: 0 \\
\hline & - \% Mujeres: 25\% & - \% Mujeres: 12,5\% & - \% Mujeres: 0\% \\
\hline & $\begin{array}{l}\text { - \% Mujeres en los } 3 \\
\text { Primeros Puestos: } 0 \%\end{array}$ & $\begin{array}{l}\text { - \% Mujeres en los } 3 \\
\text { Primeros Puestos:0\% }\end{array}$ & $\begin{array}{c}\text { - \% Mujeres en los } 3 \\
\text { Primeros Puestos:0\% }\end{array}$ \\
\hline & $\begin{array}{l}\text { - Puesto Medio de las } \\
\text { Mujeres en la Lista: } 6\end{array}$ & $\begin{array}{l}\text { - Puesto Medio de las } \\
\text { Mujeres en la Lista: } 4\end{array}$ & $\begin{array}{l}\text { - Puesto Medio de las } \\
\text { Mujeres en la Lista:- }\end{array}$ \\
\hline \multirow[t]{5}{*}{1995} & $\begin{array}{l}\text { - Total Miembros de la } \\
\text { Lista: } 7\end{array}$ & $\begin{array}{l}\text { - Total Miembros de la } \\
\text { Lista: } 7\end{array}$ & $\begin{array}{c}\text { - Total Miembros de la } \\
\text { Lista: } 7\end{array}$ \\
\hline & - No Mujeres: 2 & - No Mujeres: 0 & - No Mujeres: 2 \\
\hline & - \% Mujeres: 28,57\% & - \% Mujeres: 0\% & - \% Mujeres: 28,57\% \\
\hline & $\begin{array}{l}\text { - \% Mujeres en los } 3 \\
\text { Primeros Puestos: } 0 \%\end{array}$ & $\begin{array}{l}\text { - \% Mujeres en los } 3 \\
\text { Primeros Puestos: } 0 \%\end{array}$ & $\begin{array}{c}\text { - \% Mujeres en los } 3 \\
\text { Primeros Puestos: } 0 \%\end{array}$ \\
\hline & $\begin{array}{l}\text { - Puesto Medio de las } \\
\text { Mujeres en la Lista: } 5\end{array}$ & $\begin{array}{l}\text { - Puesto Medio de las } \\
\text { Mujeres en la Lista:- }\end{array}$ & $\begin{array}{l}\text { - Puesto Medio de las } \\
\text { Mujeres en la Lista: } 5\end{array}$ \\
\hline \multirow[t]{5}{*}{1999} & $\begin{array}{c}\text { - Total Miembros de la } \\
\text { Lista: } 7\end{array}$ & $\begin{array}{l}\text { - Total Miembros de la } \\
\text { Lista: } 7\end{array}$ & $\begin{array}{l}\text { - Total Miembros de la } \\
\text { Lista: } 7\end{array}$ \\
\hline & - No Mujeres: 3 & - No Mujeres: 2 & - No Mujeres: 2 \\
\hline & - \% Mujeres: 42,86\% & - \% Mujeres: 28,57\% & - \% Mujeres: 28,57\% \\
\hline & $\begin{array}{c}\text { - \% Mujeres en los } 3 \\
\text { Primeros Puestos: } 6667 \%\end{array}$ & $\begin{array}{l}\text { - \% Mujeres enlos } 3 \\
\text { Primeros Puestos: } 0 \%\end{array}$ & $\begin{array}{c}\text { - \% Mujeres en los } 3 \\
\text { Primeros Puestos: } 0 \%\end{array}$ \\
\hline & $\begin{array}{c}\text { - Puesto Medio de las } \\
\text { Mujeres en la Lista 3,6 }\end{array}$ & $\begin{array}{l}\text { - Puesto Medio de las } \\
\text { Mujeres en la Lista: } 6\end{array}$ & $\begin{array}{l}\text { - Puesto Medio de las } \\
\text { Mujeres en la Lista: } 5\end{array}$ \\
\hline \multirow[t]{5}{*}{2003} & $\begin{array}{c}\text { - Total Miembros de la } \\
\text { Lista: } 7\end{array}$ & $\begin{array}{c}\text { - Total Miembros de la } \\
\text { Lista: } 7\end{array}$ & $\begin{array}{l}\text { - Total Miembros de la } \\
\text { Lista: } 7\end{array}$ \\
\hline & - No Mujeres: 5 & - No Mujeres:4 & - No Mujeres: 3 \\
\hline & - \% Mujeres: $71,43 \%$ & - \% Mujeres: 57,14\% & - \% Mujeres: 42,86\% \\
\hline & $\begin{array}{c}\text { - \% Mujeres en los } 3 \\
\text { Primeros Puestos: } 6667 \% \\
\text { - Puesto Medio de las }\end{array}$ & $\begin{array}{l}\text { - \% Mujeres en los } 3 \\
\text { Primeros Puestos: } 0 \% \\
\text { - Puesto Medio de las }\end{array}$ & $\begin{array}{c}\text { - \% Mujeres en los } 3 \\
\text { Primeros Puestos: } \\
33,33 \%\end{array}$ \\
\hline & Mujeres en la Lista 4,6 & Mujeres en la Lista 5,5 & $\begin{array}{c}\text { - Puesto Medio de las } \\
\text { Mujeres en la Lista: } 4\end{array}$ \\
\hline
\end{tabular}

FUENTE: elaboración propia a partir de datos facilitados por el Parlamento Autonómico de Asturias. 
La Circunscripción Central es donde se dilucidan la mayor parte de los escaños autonómicos. Junto a la capital del Principado y las dos ciudades más pobladas, forman parte de esta circunscripción las cuencas mineras. La Tabla 4 ofrece información relativa a la poca presencia de mujeres en los puestos con mayores opciones de conseguir escaños. Así, IU es el partido con mayor presencia femenina en sus listas, aunque con porcentajes muy similares a los observados para el PSOE para cada una de las convocatorias electorales, quedando el PP bastante por detrás. De todos modos, la aparición de mujeres en los primeros puestos de las listas no acaba de tener una importancia cuantitativa relevante, si exceptuamos el caso de IU en las elecciones de 2003, donde los porcentajes de mujeres entre las 12 primeras de las listas superan ampliamente el 50\%.
Es importante señalar a este respecto que Asturias posee una estructura socioeconómica peculiar, apoyada sobre la presencia dominante durante varias décadas de la empresa pública en los sectores tradicionales de la industria, lo que ha favorecido la configuración de una política característica, y ha influido decisivamente en el perfil y la vida interna de los partidos, sobremanera los de izquierda, debido a la presencia de los poderosos sindicatos mineros (idem, p. 81). Concretamente, el Sindicato de los Obreros Mineros de Asturias (SOMA-FIA-UGT) es muy influyente en el seno del partido socialista, lo que puede explicar que los primeros puestos estén en buena parte reservados a hombres, dada la masculinización de estas organizaciones y la práctica ausencia de mujeres.

TABLA 4 - PRESENCIAFEMENINA EN LAS LISTAS ELECTORALES EN LACIRCUNSCRIPCIÓN CENTRAL,

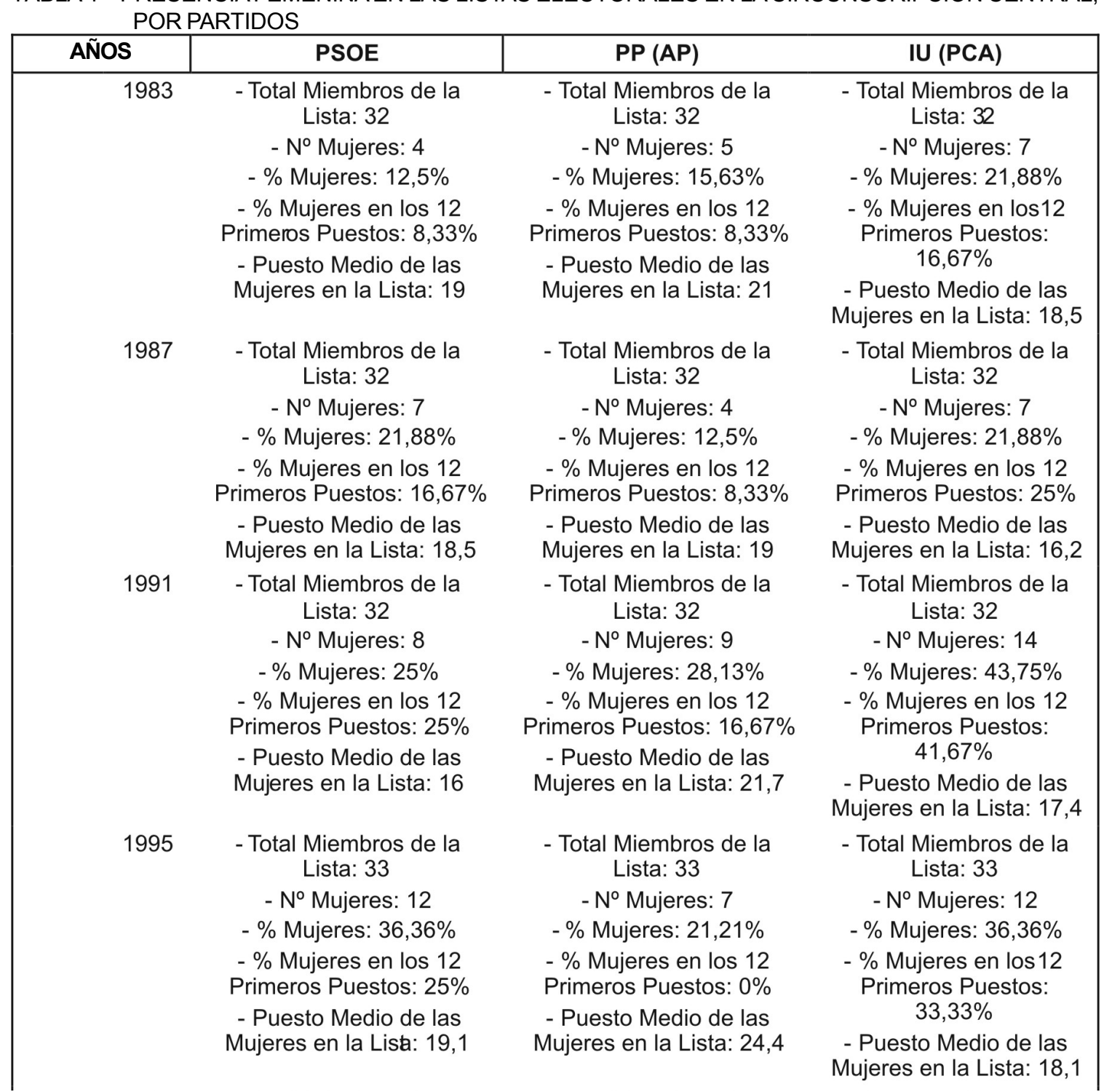




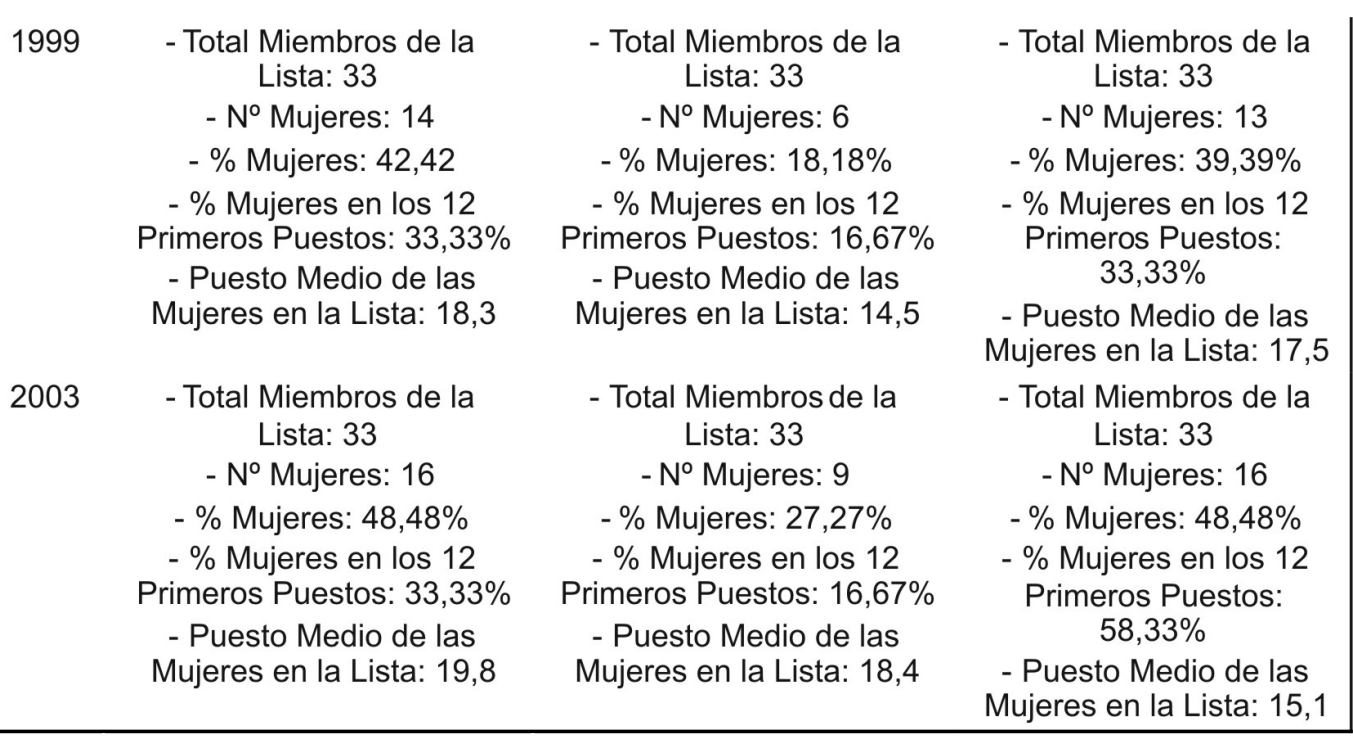

FUENTE: elaboración propia a partir de datos facilitados por el Parlamento Autonómico de Asturias.

La Tabla 5 refleja la participación femenina en las listas electorales dentro de la Circunscripción Oriental. En las dos primeras convocatorias, los mayores porcentajes se observan para el PP, y con posterioridad se aprecia un cierto equilibrio entre los datos correspondientes a los tres partidos políticos analizados. La presencia femenina en los primeros lugares de las listas es casi inapreciable hasta 1995, pero desde ese año se establece en casi todos los casos alrededor del $50 \%$. Se puede decir que a partir de mediados de la década de los noventa la distribución en las listas es paritaria lo que hace que se ajuste a los principios de representatividad social.

TABLA 5 - PRESENCIA FEMENINA EN LAS LISTAS ELECTORALES EN LA CIRCUNSCRIPCIÓN ORIENTAL, POR PARTIDOS

\begin{tabular}{|c|c|c|c|}
\hline AÑOS & PSOE & PP (AP) & IU (PCA) \\
\hline 1983 & $\begin{array}{c}\text { - Total Miembros de la } \\
\text { Lista: } 5 \\
\text { - No Mujeres: } 0 \\
\text { - \% Mujeres: } 0 \% \\
\text { - \% Mujeres en los } 2 \\
\text { Primeros Puestos: } 0 \% \\
\text { - Puesto Medio de las } \\
\text { Mujeres en la Lista: - }\end{array}$ & $\begin{array}{l}\text { - Total Miembros de la } \\
\text { Lista: } 5 \\
\text { - No Mujeres: } 1 \\
\text { - \% Mujeres: } 20 \% \\
\text { - \% Mujeres en los } 2 \\
\text { Primeros Puestos: } 0 \% \\
\text { - Puesto Medio de las } \\
\text { Mujeres en la Lista: } 5\end{array}$ & $\begin{array}{c}\text { - Total Miembros de la } \\
\text { Lista: } 5 \\
\text { - No Mujeres: } 0 \\
\text { - \% Mujeres: } 0 \% \\
\text { - \% Mujeres en los } 2 \\
\text { Primeros Puestos: } 0 \\
\text { - Puesto Medio de las } \\
\text { Mujeres en la Lista:- }\end{array}$ \\
\hline 1987 & $\begin{array}{c}\text { - Total Miembros de la } \\
\text { Lista: } 5 \\
\text { - No Mujeres: } 0 \\
\text { - \% Mujeres: } 0 \% \\
\text { - \% Mujeres en los } 2 \\
\text { Primeros Puestos: } 0 \%\end{array}$ & $\begin{array}{c}\text { - Total Miembros de la } \\
\text { Lista: } 5 \\
\text { - No Mujeres } 1 \\
\text { - \% Mujeres: } 20 \% \\
\text { - \% Mujeres en los } 2 \\
\text { Primeros Puestos: } 0 \%\end{array}$ & $\begin{array}{c}\text { - Total Miembros de la } \\
\text { Lista: } 5 \\
\text { - No Mujeres: } 0 \\
\text { - \% Mujeres: } 0 \% \\
\text { - \% Mujeres en los } 2 \\
\text { Primeros Puestos: } 0 \%\end{array}$ \\
\hline & $\begin{array}{l}\text { - Puesto Medio de las } \\
\text { Mujeres en la Lista:- }\end{array}$ & $\begin{array}{l}\text { - Puesto Medio de las } \\
\text { Mujeres en la Lista: } 5\end{array}$ & $\begin{array}{l}\text { - Puesto Medio de las } \\
\text { Mujeres en la Lista:- }\end{array}$ \\
\hline
\end{tabular}




\begin{tabular}{|c|c|c|c|}
\hline \multirow[t]{4}{*}{1991} & $\begin{array}{c}\text { - Total Miembros de la } \\
\text { Lista: } 5\end{array}$ & $\begin{array}{c}\text { - Total Miembros de la } \\
\text { Lista: } 5\end{array}$ & $\begin{array}{c}\text { - Total Miembros de la } \\
\text { Lista: } 5\end{array}$ \\
\hline & $\begin{array}{l}\text { - No Mujeres: } 2 \\
\text { - } \% \text { Mujeres: } 40 \%\end{array}$ & $\begin{array}{l}\text { - No Mujeres: } 2 \\
\text { - \% Mujeres: } 40 \%\end{array}$ & $\begin{array}{l}\text { - No Mujeres: } 1 \\
\text { - \% Mujeres: } 20 \%\end{array}$ \\
\hline & $\begin{array}{l}\text { - \% Mujeres en los } 2 \\
\text { Primeros Puestos: } 0 \%\end{array}$ & $\begin{array}{c}\text { - \% Mujeres en los } 2 \\
\text { Primeros Puestos: } 50 \%\end{array}$ & $\begin{array}{l}\text { - \% Mujeres en los } 2 \\
\text { Primeros Puestos: } 0 \%\end{array}$ \\
\hline & $\begin{array}{l}\text { - Puesto Medio de las } \\
\text { Mujeres en la Lista: } 4,5\end{array}$ & $\begin{array}{l}\text { - Puesto Medio de las } \\
\text { Mujeres en la Lista: } 3\end{array}$ & $\begin{array}{l}\text { - Puesto Medio de las } \\
\text { Mujeres en la Lista: } 3\end{array}$ \\
\hline \multirow[t]{5}{*}{1995} & $\begin{array}{c}\text { - Total Miembros de la } \\
\text { Lista: } 5\end{array}$ & $\begin{array}{c}\text { - Total Miembros de la } \\
\text { Lista: } 5\end{array}$ & $\begin{array}{c}\text { - Total Miembros de la } \\
\text { Lista: } 5\end{array}$ \\
\hline & - No Mujeres: 2 & - No Mujeres: 1 & - No Mujeres: 2 \\
\hline & - \% Mujeres: $40 \%$ & - \% Mujeres: $20 \%$ & - \% Mujeres: 40\% \\
\hline & $\begin{array}{c}\text { - \% Mujeres en los } 2 \\
\text { Primeros Puestos: } 50 \%\end{array}$ & $\begin{array}{c}\text { - \% Mujeres en los } 2 \\
\text { Primeros Puestos: } 50 \%\end{array}$ & $\begin{array}{c}\text { - \% Mujeres en los } 2 \\
\text { Primeros Puestos: } 50 \%\end{array}$ \\
\hline & $\begin{array}{l}\text { - Puesto Medio de las } \\
\text { Mujeres en la Lista: } 3,5\end{array}$ & $\begin{array}{l}\text { - Puesto Medio de las } \\
\text { Mujeres en la Lista: } 2\end{array}$ & $\begin{array}{l}\text { - Puesto Medio de las } \\
\text { Mujeres en la Lista: } 2,5\end{array}$ \\
\hline \multirow[t]{4}{*}{1999} & $\begin{array}{c}\text { - Total Miembros de la } \\
\text { Lista: } 5\end{array}$ & $\begin{array}{c}\text { - Total Miembros de la } \\
\text { Lista: } 5\end{array}$ & $\begin{array}{c}\text { - Total Miembros de la } \\
\text { Lista: } 5\end{array}$ \\
\hline & - No Mujeres: 2 & - Nº Mujeres: 2 & - No Mujeres: 1 \\
\hline & - \% Mujeres: 40\% & - \% Mujeres: $40 \%$ & - $\%$ Mujeres: $20 \%$ \\
\hline & $\begin{array}{l}\text { - \% Mujeres en los } 2 \\
\text { Primeros Puestos: } 50 \% \\
\text { - Puesto Medio de las } \\
\text { Mujeres en la Lista: } 2,5\end{array}$ & $\begin{array}{l}\text { - \% Mujeres en los } 2 \\
\text { Primeros Puestos: } 50 \% \\
\text { - Puesto Medio de las } \\
\text { Mujeres en la Lista: } 3,5\end{array}$ & $\begin{array}{l}\text { - \% Mujeres en los } 2 \\
\text { Primeros Puestos: } 0 \% \\
\text { - Puesto Medio de las } \\
\text { Mujeres en la Lista: } 3\end{array}$ \\
\hline \multirow[t]{3}{*}{2003} & $\begin{array}{c}\text { - Total Miembros de la } \\
\text { Lista: } 5 \\
\text { - No Mujeres: } 3 \\
\text { - \% Mujeres: } 60 \%\end{array}$ & $\begin{array}{c}\text { - Total Miembros de la } \\
\text { Lista: } 5 \\
\text { - No Mujeres: } 3 \\
\text { - \% Mujeres: } 60 \%\end{array}$ & $\begin{array}{c}\text { - Total Miembros de la } \\
\text { Lista: } 5 \\
\text { - No Mujeres: } 3 \\
\text { - \% Mujeres: } 60 \%\end{array}$ \\
\hline & $\begin{array}{l}\text { - \% Mujeres en los } 2 \\
\text { Primeros Puestos: } 100 \%\end{array}$ & $\begin{array}{c}\text { - \% Mujeres en los } 2 \\
\text { Primeros Puestos: } 50 \%\end{array}$ & $\begin{array}{c}\text { - \% Mujeres en los } 2 \\
\text { Primeros Puestos: } 50 \%\end{array}$ \\
\hline & $\begin{array}{l}\text { - Puesto Medo de las } \\
\text { Mujeres en la Lista: } 2,6\end{array}$ & $\begin{array}{l}\text { - Puesto Medio de las } \\
\text { Mujeres en la Lista: } 3\end{array}$ & $\begin{array}{l}\text { - Puesto Medio de las } \\
\text { Mujeres en la Lista: } 3\end{array}$ \\
\hline
\end{tabular}

Si hacemos un balance general de los datos precedentes lo primero que hay que señalar es que el ascenso de la incorporación de la mujer, tanto en las candidaturas como en los puestos de representación parlamentaria se produce de manera significativa en el año 1999, momento a partir del que el ritmo de incorporaciones se acelera. Sin duda, se confirma el papel jugado por el PSOE e IU como actores del cambio político ocurrido en España y en el Principado, y el consiguiente efecto sobre el PP. Se puede señalar que en las primeras legislaturas los partidos políticos han situado a las mujeres en las listas en aquellos puestos en los que las opciones de conseguir un escaño eran escasas. De este modo su presencia era fundamentalmente simbólica. Aunque el porcentaje de mujeres se incrementa a partir de la $\mathrm{V}$ legislatura debido a los acuerdos por parte de los partidos progresistas de asumir la democracia paritaria, los puestos medios en los que aparecen las mujeres, reduce de forma significativa las posibilidades de salir efectivamente elegidas como representantes políticas como se puede apreciar en la Tabla 6. Es decir, el porcentaje de mujeres en lista no garantiza la paridad es preciso contar con prácticas adicionales como las listas cremallera (VERGÉ, 2008, p. 147).

La Tabla 6 nos muestra la distribución por sexos de los parlamentarios autonómicos asturianos, considerando las diferentes legislaturas y cada una de las tres circunscripciones electorales existentes en Asturias. Los mayores porcentajes de presencia femenina se observan en la Circunscripción Oriental, donde no bajan del $40 \%$ desde la IV legislatura. Sin embargo, es la Central la que elige 
un mayor número de representantes, y en ella, la importancia relativa de las mujeres ha ido aumentando a lo largo del tiempo desde el inicial 12,5\% hasta los valores actuales que superan ligeramente el 30\%. Por su parte, la circunscripción Occidental es la que presenta una menor significación porcentual femenina, a pesar del notable aumento constatado en las dos últimas legislaturas.

TABLA 6 - MUJERES PARLAMENTARIAS ELEGIDAS POR CADA CIRCUNSCRIPCIÓN ASTURIANA

\begin{tabular}{|c|c|c|c|c|c|c|c|}
\hline \multirow{2}{*}{ CIRCUNS } & \multicolumn{7}{c|}{ LEGISLATURAS } \\
\cline { 2 - 8 } CRIPCIONES & $\mathbf{1}^{\mathbf{a}} \mathbf{( 8 3 - 8 7 )}$ & $\mathbf{2}^{\text {a }} \mathbf{( 8 7 - 9 1 )}$ & $\mathbf{3}^{\mathbf{a}} \mathbf{( 9 1 - 9 5 )}$ & $\mathbf{4}^{\text {a }} \mathbf{( 9 5 - 9 9 )}$ & $\mathbf{5}^{\text {a }} \mathbf{( 9 9 - 0 3 )}$ & $\mathbf{6}^{\mathbf{a}} \mathbf{( 0 3 - )}$ & TOTAL \\
\hline Occidental & 8 hombres & 8 hombres & 7 hombres & 6 hombres & 5 hombres & 5 hombres & 39 hombres \\
& $100 \%$ & $100 \%$ & $87,5 \%$ & $85,71 \%$ & $71,43 \%$ & $71,43 \%$ & $86,67 \%$ \\
& 0 mujeres & 0 mujeres & 1 mujeres & 1 mujeres & 2 mujeres & 2 mujeres & 6 mujeres \\
Central & $0 \%$ & $0 \%$ & $12,5 \%$ & $14,29 \%$ & $28,57 \%$ & $28,57 \%$ & $13,33 \%$ \\
& 28 & 28 & 25 & 28 & 23 & 23 & 155 \\
& hombres & hombres & hombres & hombres & hombres & hombres & hombres \\
& $87,5 \%$ & $87,5 \%$ & $78,12 \%$ & $84,85 \%$ & $69,70 \%$ & $69,70 \%$ & $79,49 \%$ \\
Oriental & 4 mujeres & 4 mujeres & 7 mujeres & 5 mujeres & 10 mujeres & 10 mujeres & 40 mujeres \\
& $12,5 \%$ & $12,5 \%$ & $21,88 \%$ & $15,15 \%$ & $30,30 \%$ & $30,30 \%$ & $20,51 \%$ \\
& 5 hombres & 5 hombres & 4 hombres & 3 hombres & 2 hombres & 3 hombres & 22 hombres \\
& $100 \%$ & $100 \%$ & $80 \%$ & $60 \%$ & $40 \%$ & $60 \%$ & $73,33 \%$ \\
Total & 0 mujeres & 0 mujeres & 1 mujeres & 2 mujeres & 3 mujeres & 2 mujeres & 8 mujeres \\
& $0 \%$ & $0 \%$ & $20 \%$ & $40 \%$ & $60 \%$ & $40 \%$ & $26,67 \%$ \\
& 41 & 41 & 36 & 37 & 30 & & 216 \\
& hombres & hombres & hombres & hombres & hombres & 31 hombres & hombres \\
& $91,11 \%$ & $91,11 \%$ & $80 \%$ & $82,22 \%$ & $66,67 \%$ & $68,89 \%$ & $80 \%$ \\
& 4 mujeres & 4 mujeres & 9 mujeres & 8 mujeres & 15 mujeres & 14 mujeres & 54 mujeres \\
& $8,89 \%$ & $8,89 \%$ & $20 \%$ & $17,78 \%$ & $33,33 \%$ & $31,11 \%$ & $20 \%$ \\
\hline
\end{tabular}

FUENTE: elaboración propia a partir de datos facilitados por el Parlamento Autonómico de Asturias.

Si bien como señalábamos, los partidos progresistas han iniciado un cambio importante que se refleja en el incremento de mujeres, sin embargo, como la elaboración de las candidaturas depende en exclusividad de los partidos políticos es su discrecionalidad la que contribuirá al impulso o al mantenimiento de la situación actual de poca representatividad social. Sólo en la circunscripción oriental existe paridad en las listas esto se traduce en una representación paritaria como se ha visto. Sólo con la elaboración de listas de forma se conseguirá una representación paritaria en el Parlamento.

Por tanto, observando detenidamente estos datos se confirma en Asturias que el paso de candidato a diputado es restrictivo para los efectivos femeninos y es expansivo para los masculinos (GARCÍA DE LEÓN, 1994, p. 108). Además como señala Matland, la dirección de un partido eludirá la posibilidad de nominar a candidatos que consideren "no rentables" puesto que lo que más se valora es el historial del aspirante dentro del partido y en su circunscripción electoral (MATLAND, 2003, p. 100).

A este respecto reproducimos el argumento de una representante de la elite política del Principado: "[...] generalmente es otro tipo de criterio el que hace que la gente esté en las listas, y son los apoyos que tiene dentro de su partido [...] por eso se eligen personas mayores [...] o se dice fulanito de la Corredoria porque la Corredoria son 30.000 votos [...] o sea, eso es cuota, eso es establecer una reserva en las listas para quienes representan esto. Pero también hay una cuota muy importante para el núcleo duro y los que tienen poder dentro del partido y en esa estructura las mujeres no estamos organizadas, las mujeres estamos [...] totalmente [...] al margen" (mujer, PSOE, grupo de discusión 2).

\section{CONCLUSIONES}

De acuerdo con nuestra hipótesis de partida, el sistema de cuotas ha favorecido el acceso de las mujeres a las listas de los partidos, pero esto 
no quiere decir que hayan desaparecido las dificultades de las mujeres para incorporarse a cargos representativos. De lo expuesto se puede destacar que en el caso de Asturias los partidos de izquierdas tienen mayor presencia de mujeres en sus órganos ejecutivos y en el Parlamento debido a su vinculación con los movimientos feministas, mientras que, por contra, la afiliación femenina al principal partido conservador sigue siendo notablemente superior que su participación en órganos de decisión y que su acceso a puestos de representación. Dentro de la izquierda, el PSOE consigue un mayor equilibrio entre militancia, participación en órganos directivos y acceso a puestos de representación debido al uso del sistema de cuotas.

La participación en las ejecutivas de los partidos es aún escasa debido a la cooptación masculina, a la falta de organización de las mujeres y a la triple jornada de estas. A lo largo de la historia de los partidos políticos en Asturias ha sido especialmente relevante el influjo de las redes internas sustentadas por razones históricas (económicas, sociales, sindicales, etc.). Por un lado, los contactos informales han sido y son de una relevancia significativa, así como lo es el "capital electoral" de los candidatos en el momento de la competición" (ARAUJO, 2005, p. 212). A este respecto, la mayoría de las mujeres políticas aún no cuentan con un "perfil electoral sólido", a la vista de las posiciones ocupadas en las listas y de los resultados obtenidos en términos de representación.

Pero el aumento progresivo de la participación de la mujer en puestos de toma de decisión ha influido y está influyendo positivamente en la dirección del cambio cultural en curso, de tal forma que la existencia de voces femeninas en el seno de los partidos políticos y en el sistema representativo tiende a romper con la indiferencia acerca del papel de las mujeres en la vida pública (DIZ \& LOIS, 2004, p. 218).

Amparo Novo Vázquez (anovo@uniovi.es) é Doutora em Ciência Política pela Universidade de Santiago de Compostela e Professora na Universidade de Oviedo.

Mercedes Cobo Carrasco (rlcobo@usc.es) é Doutora em História pela Universidade Complutense de Madri e Professora na Universidade de Santiago de Compostela.

Luis A. Gayoso Rico (luisgayosorico@telefonica.net) é Licenciado em Ciência Política e Sociologia pela Universidade Complutense de Madri.

\section{REFERÊNCIAS BIBLIOGRÁFICAS}

ARAUJO, C. 2005. Partidos políticos e gênero: mediações nas rotas de ingresso das mulheres na representação política. Revista de Sociologia e Política, Curitiba, n. 24, p. 193-215. Disponível em: http://www.scielo.br/ scielo.php?script $=$ sci_arttext\&pid $=\mathrm{S} 0104-$ $44782005000100013 \& \operatorname{lng}=$ en\& $\mathrm{nrm}=\mathrm{iso}$. Acesso em: 13.jan.2009.

BIGLINO, P. 2000. Las mujeres en los partidos políticos: representación, igualdad y cuotas internas. In: Mujer y Constitución en España. Madrid: Centro de Estudios Políticos y Constitucionales.

BUZNEGO, O. R. 1998. Elecciones autonómicas, sistema de partidos y gobiernos en Asturias. In: ALCÁNTARA, M. \& MARTINEZ, A. Las elecciones autonómicas en España, 19801997. Madrid: Centro de Investigaciones Sociológicas.
CAMPBELL, D. E. \& WOLBRECHT, C. 2006. See Jane Run: Women Politicians as Role Models for Adolescents. The Journal of Politics, Cambridge, v. 68, n. 2, p. 233-247, May. Disponível em: http://www.nd.edu/ cwolbrec/ SeeJaneRun.pdf. Acesso em: 20.dez.2010.

CAUL, M. 1999. Women's Representation in Parliament: The Role of Political Parties. Party Politics, London, v. 5, n. 1, p. 79-98.

CONDE, E. A. 2000. Las mujeres en el Gobierno y en los altos cargos de la Administración. In: Mujer y Constitución en España. Madrid: Centro de Estudios Políticos y Constitucionales.

COTARELO, R. G. 1985. Los partidos políticos. Madrid: Sistema.

DIZ, I. \& LOIS, M. 2004. La presencia política de las mujeres. Una comparación de la clase 
política y la opinión pública gallegas. Zona Abierta, Madrid, n. 106-107, p. 175-223.

ERIKSON, L. 1993. Making Her Way. Women, Parties and Candidacies in Canada. In: LOVENDUSKI, J. \& NORRIS, P. (eds.). Gender and Party Politics. London: Sage.

FREIXES, T. 1999: Fundamentos de la democracia paritaria: el Tratado de Amsterdam y los acuerdos internacionales. In: SAAVEDRA, P. (dir.) La democracia paritaria en la construcción europea. Madrid: Celem. Disponível em: http://www.celem.org/prog europeos/demo_paritaria2000/pdfs/ capitulo04.pdf. Acesso em: 20.dez.2010.

GARCÍA DE LEÓN, M. A. 1994. Élites discriminadas. Sobre el poder de las mujeres. Barcelona: Anthropos

GUERRA, L. 2000. Igualdad, no discriminación y acción positiva en la Constitución de 1978. In: Mujer y Constitución en España. Madrid: Centro de Estudios Políticos y Constitucionales.

LOIS, M. 2007. Mujeres y toma de decisiones. Una aproximación a la literatura especializada. In: DIZ, I. \& LOIS, M. (eds.) Mujeres, Instituciones y Politica. Barcelona: Bellaterra.

LOVENDUSKI, J. 1993. The Dynamics of Gender and Party Politics. In: LOVENDUSKI, J. \& NORRIS, P. (eds.). Gender and Party Politics. London: Sage.

1996. Sex, Gender and British Politics. In: LOVENDUSKI, J. \& NORRIS, P. (eds.). Women and Politics. Oxford: Oxford University.

1997. Representación política: dinámica de géneros y partidos. In: URIARTE, E. \& ELIZONDO, A. (coords.). Mujeres en politica. Análisis y práctica. Barcelona: Ariel.

MATLAND, R. 2003. El proceso de selección de candidatos y su impacto en la participación política de la mujer: experiencias internacionales. In: Mujer, partidos políticos y reforma electoral. Estocolmo: Instituto Internacional para la Democracia y Asistencia Electoral.

MATLAND, R. \& STUDLAR, D. 1996. The Contagion of Women Candidates in Single Member and Multi-Member Districts. The
Journal of Politics, Cambridge, v. 58, n. 3, p. 707-733. Disponível em: http://orion.luc.edu/ $\sim$ rmatlan/pdf/1996TheContagionofWomen Candidates.pdf. Acesso em: 20.dez.2010.

MÉNDEZ-MONTALVO, M. \& BALLINGTON, J. (eds.). 2002. Mujeres en el Parlamento. Más allá de los números. Estocolmo: Instituto Internacional para la Democracia y Asistencia Electoral.

MICHELS, R. 1979. Los partidos políticos. Buenos Aires: Amorrortu.

MORALES, L. 2000. Political Participation: Exploring the Gender Gap in Spain. In: GONZÁLEZ, M. J., JURADO, T. \& NALIDINI, M. Gender Inequalities in Southern Europe. London: F. Cass.

NORRIS, P. 2004. Electoral Engineering: Voting Rules and Political Behavior. Cambridge: Cambridge University. Disponível em: http:// www.pippanorris.com. Acesso em: 20.dez.2010.

NORRIS, P. \& FRANKLIN, M. 1997. Social Representation. European Journal of Political Research, New Jersey, v. 32, n. 2, p. 185-210.

NORRIS, P. \& LOVENDUSKI, J. 1995. Political Recruitment. Cambridge: Cambridge University.

NOVO, A. 2008. Posibilidades de cambio en el orden social patriarcal: el caso de Asturias. Papers, Barcelona, n. 88, p. 45-60. Disponível em: http://www.raco.cat/index.php/papers/ article/view/119864/159747. Acesso em: 20.dez. 2010 .

2009. El camino hacia el empoderamiento político de las mujeres. X Congresso Luso-AfroBrasileiro de Ciências Sociais. Braga, Portugal.

OSBORNE, R. 2005. Desigualdad y relaciones de género en las organizaciones: diferencias numéricas, acción positiva y paridad. Política y sociedad, Madrid, v. 42, n. 2, p.163-180. Disponível em: http://revistas.ucm.es/cps/ 11308001/articulos/POSO0505230163A. PDF. Acesso em: 20.dez.2010.

PANEBIANCO, A. 1990. Modelos de partido. Organización y poder en los partidos políticos. Madrid: Alianza Universidad. 
PUTNAM, R. 1976. The Comparative Study of Political Elites. Englewood Cliffs: Prentice Hall.

REY, F. 1995. El derecho fundamental a no ser discriminado por razón de sexo. Madrid: McGraw-Hill.

RÍOS, M. 2006. Cuotas de género: democracia y representación. Estocolmo: Internacional IDEA.

SANCHEZ, G. 2007. El papel de las mujeres en dos grandes partidos españoles: PP y PSOE. Política y Cultura, Ciudad de México, n. 28, p. 99-132.

TRUJILLO, M. A. 2000. La paridad política. In: Mujer y Constitución en España. Madrid: Centro de Estudios Políticos y Constitucionales.

URIARTE, E. 1995. Mujeres y política en España. Sistema, Madrid, n. 124, p. 121-136.

URIARTE, E. \& ELIZONDO, A. 1997. Mujeres en política: análisis y práctica. Barcelona: Ariel.
URIARTE, E \& RUIZ, C. 1999. Mujeres y hombres en las elites políticas españolas: ¿diferencias o similitudes?. Revista Española de Investigaciones Sociológicas, Madrid, n. 88, p. 207-232.

VALCÁRCEL, C. 1997. La política de las mujeres. Madrid: Cátedra.

VENGROFF, R., NYIRI, Z. \& FUGIERO, M. 2003. Electoral System and Gender Representation in Sub-National Legislatures: Is there a National-Subnational Gender Gap? Political Research Quarterly, v. 56, n. 2, p. 163-173.

VERBA，S., NIE，N. \& KIM，J. 1978. Participation and Political Equality: A SevenNation Comparison. Chicago: University of Chicago.

VERGE, T. 2008. Cuotas voluntarias y legales en España. La paridad a examen. Revista de Investigaciones Sociológicas, Madrid, n. 123, p. 123-150.

\section{OUTRAS FONTES}

IZQUIERDA UNIDA. 1993. Programa General IU Elecciones Generales. Madrid: Izquierda Unida.

2004. Resolución de la Comisión Permanente Federal de IU. Madrid: Izquierda Unida.

PARTIDO POPULAR. 1999. Programa Elecciones Autonómicas Asturias. Oviedo: Partido Popular.
2004. XIV Congreso Regional PP de Asturias. Oviedo: Partido Popular.

PARTIDO SOCIALISTAOBRERO ESPAÑOL. 1999. Programa Autonómico de Asturias. Oviedo: Partido Socialista Obrero Español.

2004. Resoluciones 29 Congreso Regional FSA-PSOE. Oviedo: Partido Socialista Obrero Español. 


\section{Amparo Novo Vázquez, Mercedes Cobo Carrasco and Luis A. Gayoso Rico}

Over a century after the suffragists' struggle to overcome women's political inequality, there are still significant, observable differences in women's access to positions of political power, and notwithstanding the quota system that the Spanish Partido Socialista Obrero Español (PSOE) implemented in the mid 1980s in order to increase women's representation and parity. In this paper, we start from the hypothesis that although the quota system has favored women's access to party lists, they still experience difficulties in effectively gaining access to legislative positions. Thus, with the goal of discovering what women's presence really is within decision-making spheres, the present article engages in empirical analysis of the relationship between militancy and participation in directive organs and the relationship between militancy and access to positions of representation. We look at how the PSOE has managed to establish a greater balance between militancy, participation in directive organs and access to positions of representation using the quota system. Similarly, and 
from a qualitative perspective, we look at the opinion of women politicians whom we reached through discussion groups; this has confirmed the hypothesis that we began with, particularly for the case of progressive parties. Thus, we find that while some women are able to become candidates, the poor position they tend to occupy on party lists makes it much more difficult for them to actually become elected officials.

KEYWORDS: Political Participation; Affiliation; Quota System; Political Party Executives. 


\section{Amparo Novo Vázquez, Mercedes Cobo Carrasco et Luis A. Gayoso Rico}

Plus d'un siècle après avoir commencé la lutte des suffragettes pour surmonter l'inégalité politique féminine, encore aujourd'hui, des différences par rapport aux possibilités d'accès des femmes aux postes de pouvoir politique sont observées. Quoique, à partir des années quatre-vingt, le système de quotas a été introduit en Espagne, par la main du Parti Socialiste du Travail Espagnol (PSOE), pour obtenir une augmentation de la représentation féminine et de l'égalité des sexes. Dans ce travail, 
notre hypothèse montre que le système de quotas a favorisé l'accès des femmes aux listes de partis, malgré les difficultés qu'elles continuent à avoir pour joindre les postes législatifs. De cette façon, avec le but de savoir quelle est la présence des femmes dans des contextes de prise de décision, cet article analyse empiriquement la relation entre le militantisme et la participation dans des organes de gestion, et la relation entre le militantisme et l'accès aux postes de représentation ; en observant comment le PSOE arrive à un plus grand équilibre entre militantisme, participation dans des organes de gestion et accès aux postes de représentation, en raison de l'utilisation du système de quotas. De la même façon, et depuis la perspective qualitative, nous considérons l'opinion des femmes politiques, par des groupes de discussion, qui confirmeront notre hypothèse de départ, surtout pour le cas des partis progressistes. Ainsi, certaines femmes peuvent s'en appliquer, mais à cause de la mauvaise position qu'elles occupent dans les listes, arriver aux postes de députés c'est beaucoup plus difficile.

MOTS-CLES: participation politique; affiliation; système de quotas; direction des partis. 